\title{
Translating research for policy: the importance of equivalence, function, and loyalty
}

\author{
Steve Connelly (10 ${ }^{1 \times}$, Dave Vanderhoven ${ }^{2}$, Robert Rutherfoord ${ }^{3}$, Liz Richardson (D) ${ }^{4} \&$ Peter Matthews ${ }^{5}$
}

The question of how to make academic research more useful to government, and frustration over its lack of obvious use, have long been the subject of policy makers' and scholars' attention. These have driven the global development of institutionalised links between the two communities, while also leading to a broad consensus as to why the goal is often not realised. In order to better explain the barriers, this paper takes the concept of "translation" very literally, and proposes an innovative approach, which analyses academic and policy practices using ideas from the humanities-based discipline of Translation Studies. This enables an exploration of what constitutes good translation, and in particular of the tension between keeping faith with the original material and users' understandable emphasis on functionality. The conclusion is that while some aspect of original research content must be maintained, what this is cannot be prescribed: the appropriate equivalence between original and translation is always context-dependent. This throws the emphasis on the relational aspects of translatorial action for promoting "good translation". The argument follows Christiane Nord in seeing the core issue as the moral one of a translator's loyalty to original author and user, and so also of mutual trust between academics and civil servants. This raises important questions about how such trust can be cultivated, and so finally leads to an emphasis on the importance of an endeavour shared by researchers and policy makers, which recognises and respects their different environments and the work involved in creating useful meaning from scholarly research.

\footnotetext{
${ }^{1}$ University of Sheffield, Sheffield, UK. ${ }^{2}$ Independent Researcher, Sheffield, UK. ${ }^{3}$ Department for Business, Energy and Industrial Strategy, London, UK.

${ }^{4}$ University of Manchester, Manchester, UK. ${ }^{5}$ University of Stirling, Stirling, UK. ${ }^{凶}$ email: s.connelly@sheffield.ac.uk
} 


\section{Introduction}

he question of how to make academic social science research more useful to governments has been the subject of policy makers' and scholars' attention for at least forty years (Weiss, 1975, 1979). Yet despite increasing demands for policy makers to use research, pressures on academics to have "impact" beyond the academy, and the expansion in resources and institutionalisation of links between the "two communities" (Caplan, 1979), frustration over "the visible failures of evidence to influence policy" (Gluckman and Wilsdon, 2016, p. 2) has always dogged this endeavour. The situation seems paradoxical. The very copious research on research use identifies a set of issues remarkably uniform across time, discipline and place: Weiss's early insights are still influential; the same diagnoses and prescriptions recur across disciplines (Oliver and Cairney, 2019); and Court and Young's (2003) fifty case studies, ranging from Argentina to Ukraine, suggest that experiences from the global North are broadly replicated across the world. However, while the situation is not hopeless-there is some evidence that research can influence policy (Bandola-Gill and Lyall, 2017) - in general this research on research use itself seems lacking in influence.

Oliver and Boaz (2019) identify problems of fragmentation in the creation and sharing of knowledge and a consequent weakness in the research body (which they characterise as being poorly focused on the important issues), overall leading to ineffective impact strategies. Nevertheless they are optimistic, seeing these as essentially soluble problems, needing better capturing and sharing of knowledge, and more focused research to address enduring, genuine knowledge gaps across the entire research/policy interface from "evidence" production through translation and mobilisation, as well as gaps in terms of process and who is involved (Oliver and Boaz, 2019). The breadth of this apparent ignorance suggests the possibility that new ways of thinking about the process as a whole could be useful, in order to throw light on the systemic nature of the barriers implied by their enduring nature. This paper offers such a way of thinking, and we aim to show the utility of conceptualising issues in ways borrowed from the humanities discipline of Translation Studies. This analysis takes Oliver and Boaz's agenda forward in two ways, linked by an argument for reconceptualising the idea of research translation.

The first way is to widen the analytical focus. There is a very broad consensus that research effectiveness is most efficiently promoted through personal interactions between researchers and policy makers, reflected in the quantity of scholarship on "knowledge brokers", "boundary spanners", "research partnerships" and so on. Oliver and Boaz take for granted that "using research well" requires "both users and producers of knowledge having the capacity and willingness to engage in relationshipbuilding and deliberation" (Oliver and Boaz, 2019, p. 5).They suggest more needs to be known about "who is involved in shaping and producing the evidence base", how "evidence is discussed, made sense of, negotiated and communicated" and so "what types of interfacing are effective, and how". While we of course concur with the normative consensus, given its empirical support, this focus draws critical researchers' attention away from the more normal situation, which interaction is intended to replace: of researchers and users not engaging in dialogue, but respectively publishing research and drawing on these publications in the policy making process. Research on this situation, and thus prescriptions for improvement, are dominated by an unhelpfully simplistic, linear understanding of research translation (Rushmer et al., 2019). Therefore, we aim to broaden the scope of Oliver and Boaz's questions: we suggest there is a need for more sophisticated analysis, which is applicable to all the ways through which research products reach "users", whether or not interaction is involved.
Secondly, while recognising the value of social scientific contributions to understanding research use, we take our cue from another of Oliver and Boaz's proposed avenues for exploration. They ask whether evidence "can...survive the translation process?" (Oliver and Boaz, p. 6) and suggest that understanding this could fruitfully draw on theories of communication-theories of how messages have different meanings for their originator and their audience. These are indeed important, showing how cognitive content is only part of the communication process, along with message design and materiality shaping what is actually understood by the audience (Kress, 2010; Connelly et al., 2015). Here however, we focus on a different approach to theorising the first, perhaps most obvious of these communicative elements: the fate of the cognitive content of a "text" during translation. The rationale for this is to redress a relative lack of critical focus on this content in research use scholarship. The literature appears to be divided between linear, positivistic approaches, which take as given the idea that a core meaning can be "translated" "from bench to bedside" (Woolf, 2008) or similar, and a critical response, which problematises this assumption and engages with the social and political aspects of evidence production and use. As a label for what happens when the outputs of research are taken up by non-academic "users", "translation" is much-used yet clearly ambiguous (Freeman, 2009; Ingold and Monaghan, 2016; Nutley et al., 2007). The dominance of one conceptualisation in the simplistic, linear understanding of research use has led critical scholarship to be either sceptical of the label's utility altogether (Greenhalgh and Wieringa, 2011; Penuel et al., 2015) or to interpret it very differently, inspired by actor-network theory (ANT) to emphasise the transformation and "betrayal" of the source inherent in translation and downplay continuities in what is "carried across" (Callon, 1986; Law, 1997; Rhodes and Lancaster, 2019).

Here, we argue for a middle way: that while linear understandings are clearly inadequate, moving meaningful content from one group to another-from researchers to the users in the non-academic worlds of practice and policy making-is constitutive of the very idea of research use. Our contention is that understanding the work done on, and with, that content by all those involved in this "translation" will help to explain both problems with research use and possible solutions. In this paper we show how concepts drawn from the humanities discipline of Translation Studies can aid such analysis, since for over two thousand years scholars in that discipline have been grappling with what it means to turn texts from one language into another, to move semantic content between cultures, and what is valued in the output of a translation (Munday, 2012). We expand on this below, but emphasise here that we are looking beyond the conceptualisations and uses of "translation" which are probably familiar to most scholars of research use. Our explicit aim is to learn from the concept's original "home" in the humanities, and draw on arguably its least metaphorical, most literal meaning to illuminate analogous processes which take place in research use, and which are not accessible through either linear or transformative conceptualisations.

In this paper, we first set the scene by clarifying our conceptualisation of the research-policy relationship and how this relates to the existing literature and uses of the concept of translation. The bulk of the paper introduces three ideas from Translation Studies-"equivalence", "function" and "loyalty." These are linked by their roles in the development of ways of thinking about the desirable relationship between a "source text" and its translation, as theorists and practicing translators explored the dilemma posed by the tension between sustaining fidelity to an original source and producing a translation, which is 
functional for an audience (Nord, 2018; Schäffner, 2018). We show how each in turn leads to useful insights into research translation, through exploring empirical material from a pair of research projects concerned with the use of academic social science research by a UK central government ministry. As with any case study, the details are unique to their context. However, given the apparent ubiquity of the issues faced by those attempting to make research more influential, and the nature of the middlerange conceptual development presented, we suggest that the analysis has very general relevance and practical implications.

Taking research into policy making. Despite the fragmentation of the research base noted by Oliver and Boaz, systematic reviews identify a consistent set of enablers and barriers, many first identified by Caplan (1979) and subsequently widely corroborated empirically. These are principally the importance of political and institutional context, the nature and relevance of evidence, and the nature of links between academic and policy communities (see reviews by Court and Young, 2003; Gaudreau and Saner, 2014; Mitton et al., 2007; Nutley et al., 2007; Oliver et al., 2014; Oliver and Cairney, 2019). Proposed solutions are similarly consistent, with Oliver and her colleagues' systematic review typically identifying "timely access to good quality and relevant research evidence, collaborations with policymakers and relationship- and skills-building with policymakers" (Oliver et al., 2014 , p. 1) and the "need for high-quality, simple, clear and relevant research summaries, to be delivered by known and trusted researchers" (2014, p. 9).

However, the theoretical underpinning for these is seen to be insufficient to provide a secure base for improvement (Ingold and Monaghan, 2016; Boswell and Smith, 2017; Oliver and Cairney, 2019). The issue of how key elements of the processes are conceptualised is fundamental, in particular the issues of who is involved and the relationships between them, and how research outputs are reworked in the process of being taken into the policy process (Boswell and Smith, 2017; Rushmer et al., 2019). Two dominant, conflicting positions are clearly visible both in the practical world of research use and in academic analyses, which share frustration over the lack of research "impact" but little else.

The policy world's self-understanding is still dominated by a linear, rational model (Boswell and Smith, 2017; HM Treasury, 2020), within which academic research has a clear role in providing evidence about the nature of problems and about "what works." This conceptualisation underpins much of the research on how to improve researchers' ability to "push" their knowledge into the world and on policy makers' ability to "pull" it in effectively (Rushmer et al., 2019).

This model has long been criticised on the grounds that it does not accurately describe policy making or the role of knowledge and research in the process (Lindblom and Cohen, 1979; Weiss, 1979). Despite their differences, alternative analyses concur that policy making is neither rational nor linear, being complex and political, involving many stakeholders with multiple goals operating in contexts of institutional complexity (Boswell and Smith, 2017). In parallel, more sophisticated accounts have been developed of how research is actually used, many drawing on Weiss's suggestions that alongside instrumental uses, research also serves an enlightenment function, through introducing ideas, which change how issues are conceptualised. It is also used politically, to bolster already-taken decisions, and tactically, when the symbolic visibility of the research process itself is what matters (Weiss, 1979).

At the heart of the issue of research translation is the idea of distinct groups, the producers and users of research outputs, between whom there are troublesome boundaries, which need to be traversed in some way in order for research to be used. Most of the academic and policy literature is dominated by the idea of "two communities", which agree on the need for evidence-based policy making, but have very different cultures (Caplan, 1979; Wingens, 1990). The boundary between them is thus seen as one which presents barriers to intercultural communication, which can be overcome by aligning languages, increasing information about what knowledge is available, coproduction and other means of learning about the others' domain, and employing individuals who can span boundaries and broker communication (Oliver et al., 2014). Despite its domination of the practice of research use, and research on this (Rushmer et al., 2019), this conceptualisation is arguably over-individualistic, and neglects more structural factors (Nutley et al., 2007; Wingens, 1990). An alternative view suggests that there are two systems, with different functions and therefore principal logics.

Wingens (1990) claims that governments will necessarily use research pragmatically and selectively, given their need to "establish collectively binding decisions" (p. 35) (that is, to govern). In contrast, academic products are generated in a system that (in principle) privileges truth, and will therefore have to be transformed in some way in order to be comprehensible and functional for government. As government researchers writing to an academic audience, Phoenix and her colleagues describe how their world does "not value their research by journal impact and funding. Instead, the value of research is assessed according to its impact in decision making" (Phoenix et al., 2019, p. 3). This view suggests that the boundary between the systems will not be traversed simply by individuals developing greater intercultural competence. However, positions differ on its permeability. Boswell and Smith (2017) point to theories that suggest that the systems are too "autonomous" for "flows, diffusion or causality" between them (2017, p. 6); in contrast Smith and Joyce (2012) point to network theories, which show that much policy making spans organisational boundaries rather easily, among groups, which share interests and values. Wingens argues for a middle ground, recognising the systemic, structural differences but suggesting that communication will be possible, since "neither scientists nor policymakers are completely predetermined by the social systems in which they have to act" and they are likely to have shared experience, insights, and language (Wingens, 1990, p. 39). We share his position, on both the general theoretical nature of the relationship between actors and institutional contexts, and on empirical grounds: our own research and that of Phoenix and her colleagues points to exactly the kind of shared experiences that Wingens postulates.

Regardless of how the process is conceptualised, there is a consensus that intercultural communication is facilitated by dialogue of some kind across these boundaries. An extensive and varied literature explores ways in which this may be done; while we cannot explore this in detail here, we sketch out some of its contours in order to show how our work complements it through investigating what is involved in the work of translating across boundaries. This literature can be characterised by the organisational form it explores or proposes. The two principal differences are: (a) between whether a "knowledge broker" (often envisaged as a third party, a "boundary spanner") is seen as valuable in bridging the gap between research producers and users, or if exchanges between members of the two communities are sufficient; and (b) whether the brokering task is individual or collective, to be conducted at an organisational level. The individual knowledge broker is a salient figure in the literature, typically conceived of as a person distinct from either community, with specific intercultural skills. They occupy an intermediary position, which enables them to bridge gaps and connect communities (Kislov et al., 2016, 2017) exactly because the 
differences between Caplan's two communities mean that "neither researchers nor decision makers are best placed to drive the translation, transfer and implementation of...research evidence" (Ward et al., 2009, p. 2). Proponents of boundary spanners in this context suggest that they may improve both the process of creating relevant research and the capacity of users to use it (Bednarek et al., 2018) through a combination of working directly with the content of research as "knowledge managers", working as "linkage agents" facilitating interchange between researchers and users, and as "capacity builders" sharing their expertise with these groups (Ward et al., 2009; Kislov et al., 2016). How the first of these is conceptualised varies, depending on how knowledge is thought to transfer from one domain to another: it may be about managing existing ideas, "identify[ing], select[ing] and obtain[ing] information from the environment and efficiently transmit[ting] it within and across the organizations according to needs" (Kislov et al., 2016 p. 474), or be a rather more interpretive role in which brokers have some contribution to creating useful knowledge (Ward et al., 2009).

While the value of individual brokers is widely recognised, there are also risks associated with them, principally of individuals acting as "policy advocates" rather than "honest brokers" (Pielke, 2007), and of creating inefficiencies by not drawing on a wider range of expertise (Bandola-Gill and Lyall, 2017; Dewaele et al., 2021). Both drawbacks can be avoided, it is claimed, by moving from an individual to a collective, organisational model (Kislov et al., 2017), in which members of both communities work across the boundaries. This may be formalised in "research-practice partnerships"-essentially sites of coproduction of knowledge, which require the development of new practices by all those involved as they engage in joint work across the boundaries (Penuel et al., 2015; Vindrola-Padros et al., 2017). An alternative, individual way of dispensing with third party brokers and achieving direct communication between researchers and users is through embedding researchers in user organisations (Vindrola-Padros et al., 2017; Ward et al., 2021).

All of these approaches have an obvious appeal, given the persuasiveness of the "wide and interdisciplinary literature that sees effective knowledge production and 'research use' as social, situated and contextually mediated processes" (Ward et al., 2021 pp. 17-18). However, none is straightforward, given the differences between communities and systems that dialogue and brokerage are intended to overcome. They all involve new "boundary practices" (Penuel et al., 2015), requiring time, energy and skills, delivered either by specialist third parties or achieved through researchers and users developing new capabilities. These include cultural understanding and sensitivity, and interpersonal and communicative skills (Kislov et al., 2017). Some of these are learnable, but to some extent they also come down to "personal characteristics and dispositions" (Vindrola-Padros et al., 2017, p. 74). Given these factors, along with the very real structural constraints, which inhibit many academics from getting involved in knowledge transfer activities (Matthews et al., 2018; Oliver and Cairney, 2019; Oliver and Boaz, 2019), the norm is probably not interaction but the less resource-demanding (and less effective) processes of "pushing" and "pulling" (Rushmer et al., 2019) by academics disseminating their results through their own writing, and potential users gathering published information.

Common to all this literature is the taken for granted difference between creators and users of research, and thus of more-or-less easily crossable boundaries between them. While the more simplistic, linear conceptualisations focus on how best to communicate research outputs, more sophisticated approaches are concerned principally with the social processes of interaction involved in the tasks of translation, facilitation, capacity building and joint working, and not with the cognitive content of "evidence." Yet to respond to Oliver and Boaz's call for research on "transforming evidence translation and mobilisation", we contend that understanding "how evidence is discussed, made sense of, negotiated and communicated" (Oliver and Boaz, 2019 p. 5), and how the manifest barriers to translation actually work (Mitton et al., 2007; Oliver et al., 2014), must involve a closer look at what is actually done to the substantive content of research outputs as they are transferred into the policy realm. In all but the most naïve conceptualisations of this, some degree of transformation will take place in order to make this transfer possible. In order to examine this more closely, we push the common trope of "translation" further than is usual.

Translation as metaphor or practice? "Translation" has become a widely used metaphor for what happens to research in its passage from academia to users (Freeman, 2009). Often used in a very general sense, without theoretical commitments to what translation might actually involve (see e.g., Bednarek et al., 2018; Oliver and Boaz, 2019), the term also has a range more specific meanings tied closely to the broader conceptualisations of the nature of the research-policy relationship outlined above (Rushmer et al., 2019). Where this relationship is seen as simple and linear, translation is effectively a synonym for "transfer"; this conceptualisation underpins the mass of activity on improving the transfer of "what works" from research to practice (Woolf, 2008; Rhodes and Lancaster, 2019). However, just as the empirical weakness of the rational policy model has led to its widespread critique and rejection by policy scholars, so there have been two broad critical responses to this conception of "translation".

Some scholars have followed the radical interpretation of the term emerging from actor-network theory (ANT) and science and technology studies (STS), which emphasises change, rather than the simple "carrying over" of a well-defined entity. ANT's founder claimed that "to translate is to displace" (Callon, 1986, p. 223) - faithful translation is impossible, as it involves a "necessary betrayal" (Law, 1997, p. 1). Ingold and Monaghan (2016) draw on STS-influenced policy theory (Lendvai and Stubbs, 2007) to see research translation as something which "does not need to be entirely faithful to the original and involves a process of replication, imitation and differentiation" (2016, p. 173). Rhodes and Lancaster (2019) take a more radical ANT approach, abandoning the idea of fidelity altogether and explicitly distancing themselves from the idea that anything substantive endures; for them, research outputs are "transformed", "worked-with into different things" (p. 2).

The alternative critical response has been to view "translation" as irredeemably attached to linear conceptions of research use, and so to reject the term altogether (Greenhalgh and Wieringa, 2011; Penuel et al., 2015). Penuel et al. (2015) claim it leads to "an impoverished way of thinking about the relation of research and practice" (p. 183) and so to inappropriate proposals for closing the gap between them. In its place they favour concepts relating to "interaction" (such as partnerships) and "practice" (such as phronesis) in order to better capture the "complex, non-linear and locally contingent" processes (Greenhalgh and Wieringa, $2011 \mathrm{p}$. 507) through which knowledge generated by research is related to practice. This reconceptualisation is inextricable from the consequent normative, practical agenda of promoting interactive approaches to enhance research effectiveness.

Both critical responses are unhelpful in two ways. Firstly, the conclusions in favour of interaction remove other practices from critical analysis. Secondly and more fundamentally, both are problematic in that at the core of the idea of research use must be a concern with that which is "carried over". Some aspects of 
academic knowledge must be capable of being preserved as it is brought into the realm of policy making, since otherwise there would be no reason to value research-even if this involves more transformation than is envisaged by the everyday positivism of the policy making and implementation science communities. This criticism does not entail a retreat to the linear model, but takes us to a middle ground, which recognises the force of the critical arguments but maintains a realist commitment to the "element of underlying entity" explicitly rejected by Rhodes and Lancasterthe element captured by Steiner's notion of "invariance within transformation" (Steiner, 1998). Steiner was concerned with literary translation, rather than research use: here we are proposing that useful intellectual resources for understanding the latter can be found in Steiner's humanities discipline of Translation Studies.

This varied and complex discipline sits at the intersection of linguistics, language studies, comparative literature and cultural studies (among others), drawing on all of these for theoretical resources. Its roots are ancient, going back to classical Roman concerns with translating Greek poetry into Latin, and hardfought early Christian controversies over Biblical interpretation (Munday, 2012). Throughout it has inescapably been concerned with how the content of a source is related to its translation, since while some relationship is constitutive of the idea of translation (as opposed to the creation of originals) this cannot be simple transfer, as by definition the original is not readily intelligible to the target audience (Sakai, 2006).

The resonances with research translation are clear, and our suggestion is that Translation Studies' central concern with invariance within transformation complements the research use literature. Yet apart from a very brief paper by Engebretsen et al. (2017), what the discipline has to offer has been curiously ignored by policy scholars, despite Freeman speculating on its value in 2009 (Freeman, 2009). In a single paper we clearly cannot explore the entire discipline, nor claim to have identified all the lessons it might have for research use scholarship and practice. Rather we have selected a set of linked concepts-equivalence, function, and loyalty - which have been central to the core question of what it is that makes a good translation (Schäffner, 1997).

Following Siggelkow's argument (2007) for linking conceptual development with the exposition of cases in order to show how abstract concepts are manifested in reality, we use the rest of the paper to explore how ideas from Translation Studies provide tools for better understanding "research translation", in the context of empirical material drawn from two linked research projects. In the next section we describe the projects and methods of data collection and analysis. We then examine Translations Studies' (ultimately unconvincing) attempts to establish equivalence between source and product as the criterion of translation quality. We follow the discipline's turn to a focus on a translation's function, but then suggest, following Nord (2018), that privileging function is also problematic, and show the value of augmenting this with a concern for loyalty, and so for interpersonal rather than intertextual relationships.

\section{Methods}

The projects were funded by the UK Research Councils' Connected Communities programme (AHRC, 2012). Working collaboratively with researchers from the Department for Communities and Local Government (DCLG: the ministry then responsible for localism, local and community governance, planning and housing in England), the main project focused on the impact of a set of academically authored policy briefings. It also ranged more widely across the production and use of research by the civil servants. The project team comprised academics involved in producing the policy briefings (including Vanderhoven, Richardson, and Connelly), one who had not been involved (Matthews), and a DCLG social researcher (Rutherfoord). The approach was interpretive and ethnographic, exploring both how academics and civil servants understood their roles, and their actual practices. Vanderhoven, Matthews and Rutherfoord interviewed eleven civil servants and all eleven of the academics who produced the policy briefings. Vanderhoven spent three separate weeks observing and interviewing within DCLG, and we ran four workshops on research translation and use with the same groups of civil servants and academics. The interviews were digitally recorded and professionally transcribed. Detailed field notes were taken at the workshops, and by Vanderhoven to record his observations in the DCLG offices.

A follow-on project involved action research by Connelly and Vanderhoven, working with some of the same civil servants to broker connections between potentially relevant civil service policy teams and a wider set of 25 academics funded by the Connected Communities programme. Successful connections took the form of four face-to-face meetings, which were digitally recorded. We have also drawn on "on the record" email communications between these two authors and academics and civil servants, reflecting on the findings of both projects.

Our principal ethical concern was with confidentiality, both to protect individuals and ongoing policy processes. The overall management of this risk was done through continuous discussion about risk between academics and the civil servants most closely connected with the project, minimising individual identifiers in published material, and checking the use of all quotations from civil servants. At the individual level, informed consent for interviews and for the use of emails was obtained through sharing an information sheet and then confirming consent on a standard form. For meetings and participant observation, individual consent forms were not used, but agreement was obtained from all those involved at the outset. Precautions to protect individuals included sharing transcripts and other materials only among the academic team and not with the civil servants most closely involved. Overall ethics approval for the project was obtained from the University of Sheffield Research Ethics Committee.

A first inductive analysis, drawing out insights into how research use was conceptualised and practiced by those involved, and the structural constraints on this, was carried out through manual thematic coding (Braun and Clarke, 2006) of all the interview transcripts, field notes and reflective emails. This formed the basis for the project reports. We then reinterpreted the data using a new conceptual framing drawn from Translation Studies, for the reasons outlined above. This re-coding was thus more directed (Hsieh \& Shannon, 2005) than the original analysis, using as core themes the three concepts taken from Translation Studies theory introduced briefly above and which structure the discussion below: equivalence, function, and loyalty. Sub-codes within this framework, such as ways of dealing with academic texts and judging research quality, were developed inductively. In presenting this we include some quotations taken from the interviews and emails to illustrate the case being made. These are relatively sparse and mainly brief, partly because in the nature of the discussions in the meetings and interviews there were rarely self-explanatory passages, and partly because of the need to protect the individuals and policy processes concerned. They are thus selected to be both representative and intelligible to illustrate and reinforce the points being made. The observational data is presented particularly sparingly: it turned out that the most useful data directly concerned with translation came from the action research, which was also the most sensitive in terms of preserving confidentiality around ongoing policy initiatives. 


\section{Taking translation theory seriously}

Can "equivalence" be the goal?. We start with the concept of equivalence. On the one hand this resonates with everyday understandings of "translation" and with simple notions of research use, while on the other within Translation Studies it gets to the heart of the difficulties of defining what is carried over, and how this might be done well. Translators' traditional focus was on preserving as much of the content of a "source text" as possible, but how to do this faithfully was a matter of longstanding debate over whether translation should be word-for-word or "sense-forsense" - a debate which in the twentieth century matured into a focus on the concept of "equivalence" (Munday, 2012). Unsurprisingly, we found the expectation of equivalence (in a rather naïve sense) in good currency in the policy world. We were told by one government social researcher (GSR) that the need for "some sort of translation of these ideas into language and concepts that policymakers can understand" should be met "without losing the richness and the nuance of your findings-we don't ever want to lose that at all". This is straightforwardly linear: as noted above, this assumption that academic knowledge can and should be accessible through translation without loss of content is characteristic of policy makers, and built into official accounts of the role of research in policy making.

However, according to Translation Studies, achieving equivalence of every aspect of a source is impossible (Sakai, 2006): translation necessarily involves some degree of change, and loss, from the original. What remains "invariant" cannot even be an entirely shared meaning (contra Freeman, 2009), given the different cultural and linguistic settings of the source and target texts (Sakai, 2006). Elaborating the concept of equivalence thus involved identifying what is significant in a source and therefore must be maintained (Nida, 1964). Within the academic discipline this spawned many different categorisations of equivalence, and the recognition that what was to be preserved differed between types of source text. For research-based texts the idea that a translation should provoke a similar response, an "equivalent effect", in the target group as the original did for its audience (Nida, 1964), seems particularly helpful. Fundamentally such a response should be to comprehend the core ideas and trust them on the basis of some kind of warrant: the translation should make the same case as the original. Newmark (1981) adds a cultural aspect, suggesting that while a translation of a non-literary text should be accurate in conveying the content of the source, it should also be oriented towards the target audience's linguistic, stylistic and cultural norms.

However, the fact that within the discipline there was no resolution of the multiplicity of possible choices over what equivalence could mean (Adamska-Sałaciak, 2010), and so no consensus over what should be preserved or abandoned in translation, points to a fundamental problem with the approach. In part this arises because the idea of equivalence rests on the challengeable assumption that meaning (as pure content) can be transferred between languages and cultures, independent of the communicative and wider context. This may sometimes be a reasonable approximation: in the research use context, a single simple quantitative "finding" may be easily transferred. For example, the "number of neighbourhood planning projects initiated" has much the same content whether in an academic publication (e.g., Wargent and Parker, 2018) or on an infographic poster on a DCLG office wall. Such transfer cannot, however, be generally achievable, as any interpretation of such a finding (or of any more complex idea) depends on the audience's understanding and needs. In this example, while this number figures in academic discussions on local democracy (e.g., Bradley, 2015), for the civil servants its key meaning is to show that the neighbourhood planning policy was successful.
The debates continue within Translation Studies, driven by the irresolvable tension between resistance to sacrificing the "richness of the meaning" and "authority" of the source (Newmark, $1991 \mathrm{p}$. 106) and equivalence's common-sense attractiveness, and the apparent impossibility of specifying what constitutes equivalence (Adamska-Sałaciak, 2010). For us, the concept usefully reinforces a focus on how translation conveys something, and prompts consideration of which aspects of a piece of research are essential for a given audience, as well of that audience's communicative norms. Yet the lack of resolution within the discipline suggests that seeking an a priori definition of equivalence between source and target texts is ultimately unworkable, and that alternative criteria are needed to characterise and evaluate this elusive thing which is carried over. Within Translation Studies these concerns, reinforced by broader cultural and systems "turns" in the discipline, prompted a reorientation away from a linguistic approach (focused on texts themselves) towards viewing translation as a social practice driven by its function for the target audience (Munday, 2012).

Functional translation. The possibility of maintaining equivalent content and also being functional for the user underpins the linear conception of translation in the research use literature. In contrast, functionalist Translation Studies theorising rejects the possibility of specifying what equivalence should mean independent of context. Instead it defines a good translation principally in terms of utility-one which is adequate and appropriate, given its function for the audience (Schäffner, 1997). "Adequacy", "appropriateness" and "function" are seen as always contextualised, determined by a "situation-in-culture" (Nord, 2018), and therefore needing to be assessed by translators as knowledgeable actors. One aspect of the context is the broader power structures and externally imposed norms within which translators work, theorised within the discipline by Chesterman (1997), Lefevere (1992) and Hermans (2000) in ways broadly similar to social scientific accounts of power within institutions, including in the context of research translation (see e.g., Freeman, 2009; Oliver and Boaz, 2019). Our focus here is therefore on an aspect less visible in social scientific accounts, but highlighted by Translation Studies with its focus on the practices of translation. This is the set of norms about the translation process itself, which govern what counts as appropriate translation (Toury, 1995).

The core of the functionalist approach is a hierarchical set of rules laid out by Reiss and Vermeer (2013, p. 90). The first of these rules establishes the primacy of function: everything else is secondary to the utility of the translation to the end user. This includes the nature of the relationship between a source text and its translation, which is covered by subordinate rules: Rule 2 defines translation as an "offer of information" in the target language and culture "concerning" an offer of information in the source language; Rule 4 requires "coherence" between the information received by the translator, their interpretation of this and the final text. The obvious vagueness of "concerning" and "coherence" is deliberate, and allows the relationship between the content of a source and its translation to be context-dependent, determined solely by the function (or skopos, in these theorists' terms) (Nord, 2018). "Equivalence" as a requirement has disappeared.

In these terms, the linear policy making model assumes a single skopos uniting impact-hungry scholars and rational, evidence-led policy makers, all seeking to give government policy the best possible knowledge base. However, in the UK central government policy context, there is a third group involved. These are the GSRs or "analysts", a civil service cadre distinct from the policy teams, who officially "provide government with objective, reliable, relevant and timely social research; support the development, 
implementation, review and evaluation of policy and delivery; [and] ensure policy debate is informed by the best research evidence and thinking from the social sciences" Civil Service, $2021)^{1}$.

The GSRs are curiously absent from most accounts of the research-policy relationship (Phoenix et al., 2019; Hampton and Adams, 2018). Their official role as neutral conveyors of knowledge fits neatly into the government's linear conception of research transfer, but our own research corroborates that of the few other researchers who have paid attention to the GSRs in showing their creative agency (Cooper, 2016; Hampton and Adams, 2018; Ingold and Monaghan, 2016; Nutley et al., 2007; Kattirtzi, 2016; Phoenix et al., 2019). They are not passive transmitters of material but have important roles as "knowledge managers" (Ward et al., 2009) in matching up relevant research findings with policy needs, and in turning research outputs into material usable by the policy teams. They are thus clearly knowledge brokers of a sort, part of whose role is as translators (Mulgan, 2013) in the strict sense of people turning material from one language into another. They see themselves as brokers (Phoenix et al., 2019), and often have educational and professional backgrounds outside the civil service, which provide the necessary cultural and linguistic competence for this role. Corroborating Wingens' dismissal of the idea that "social scientists and policy-makers inhabit two separate worlds" (1990, p. 33), many GSRs have academic backgrounds: as one GSR with a doctorate said to us, "Before I was a civil servant? I taught Philosophy".

However, as civil servants the GSRs are rather unusual brokers, compared to the independent third parties envisaged by the literature discussed above. Although they act as intermediaries between academics and policy teams they are also part of the government system, and so are constrained by its orientation towards decision making (Wingens, 1990). So while their skills may enable them to "effectively construct a bridge between the research and policy communities" (Phoenix et al., 2019, p. 2, quoting Nutley et al., 2007) and provide a more permeable boundary between academia and government than might be expected, the Civil Service Code (Civil Service, 2015) is very clear that they must be neutral within government: the GSRs are not neutrally positioned between the two communities and are prohibited from working as "issue advocates" (Pielke, 2007). Their role involves working across the spectrum from the very interactive (and resource-intensive) engagement envisaged by the boundary spanning and research partnership literature, through to "pulling in" published material (Rushmer et al., 2019).

Despite the complexity added by the intermediary role of the GSRs, in practice we found a broadly shared skopos across the three groups. The policy teams were genuinely interested in using research to inform their work. One characteristically described their task as "to be able to marshal the evidence for and against options that are within the sphere of the possible... [When] a minister asks "can we do X? Why can't we do Y? What are the options for addressing Z?" ...we have to come up with a list of bright ideas. Having an easily-accessible and then relatively easily-digestible evidence base to inform that thinking is valuable."

The GSRs' purpose was clear, and complemented the policy teams' aspirations. It was given typical expression by two GSRs: "my ambition is really to make sure the policy team have access to the latest relevant evidence to underpin the policy details" and "we want to be as useful to [the policy teams] as possible and to make things as easy as possible. So it is trying to interpret things and what this could mean". There were nuances in their aspirations. While for one "whether they choose to use [the 'latest relevant evidence'] or not use it, that is at their discretion, but at least I'm doing my job to make sure they have access to it", for others the point was to influence policy making, whether directly or through "enlightenment" effects (Weiss, 1979). In pursuit of making the mass of available evidence useful, the analysts deliberately offered new information, in Reiss and Vermeer's sense, for instance valuing conceptual work such as "think[ing] a bit more creatively and put[ting] a framework around things" in order to stabilise and bring order to the policy teams' "amorphous and changing" issues.

The extent to which academics' skopos actually matters depends on how they engage with the policy process. Academics' aspirations for their scholarly outputs are in principle irrelevant: as source texts, which the GSRs translate, they are simply raw material. However, researchers seeking impact often translate their own work from their academic source languages into something intended to be comprehensible and influential in the policy community -as, for example, some of this paper's authors did with the policy briefings produced for DCLG. Their purposes may range from the most instrumental desire to communicate specific findings through to changing how the government conceptualises particular issues. Working interactively with the policy world also presupposes similar intentions to inform and influence, as academics enter conversations with policy makers and strive to be understood.

However, while we generally found this shared, broad purpose of using research to inform policy, at a more detailed level this is insufficient as a guide to achieving adequate translations. For research to be useful it must be translated to fit specific needs of the policy teams, and these are typically precise, dynamic, and unpredictable. So how might this be achieved?

Functionalist translation theory emphasises the role of the target text receiver in setting the skopos for the translation, ideally through explicit instructions defining a context-specific relationship between source and translated material. The necessity for such a "brief" seems obvious: unless a translator is very familiar with the needs and conventions of the target group, "translating without clear instructions is like swimming without water" (Nord, 2018, p. 72). Yet academics, including ourselves and many of those with whom we worked in the action research project, are often in this situation. Without a detailed grasp of the policy fields to which they might contribute, or of the complexity of the GSRs' and policy teams' worlds (Oliver and Cairney, 2019; Phoenix et al., 2019), they are unable to produce useful translations of their work. ${ }^{2}$ This is why the GSRs' role is central, as they search for relevant academic texts and rework these for the policy teams. Their knowledge of both systems is crucial to this translation work: as well as having detailed knowledge of the policy teams' interests, one GSR described how "I've always thought it's an analyst's job to be on top of the academic literature", by, for instance, following relevant journals and academics on social media.

Yet even for well-informed and interculturally competent GSRs, attempting to be more proactive by producing briefs for academics may be challenging. Language and cultural issues can create barriers to communication into the academic world: writing a brief requires an understanding of that world and translation of policy needs into language intelligible to academics. So, for example, an analyst's attempt to define for us their immediate research needs contained (from our academic perspective) a mix of genuinely researchable questions, questions which would require unfeasibly large resources to answer, and normative/evaluative questions, which are not easily researched (such as "how can we best support the creation of more integrated communities?").

Nord's proposed solution to the problem of inadequate briefs is clarity through dialogue (Nord, 2018), in the same way that 
interactive approaches should enhance research translation. The GSRs saw interaction as core to their effectiveness in translating for the policy teams, since "if we don't understand the policy issues they're facing on a day-to-day basis, we can't respond." Interaction across this boundary was relatively simple, particularly when GSRs and policy teams were co-located. Academics may mirror this through sustained partnerships (Penuel et al., 2015) or in the role of embedded researchers, able to interact regularly, both formally and informally, with users and so produce relevant research (Vindrola-Padros et al., 2017). Less formally, the DCLG GSRs had close relationships with a very few academics, like the one characterised as being "really good at coming in and just having a chat and offering to do seminars and that kind of thing." As noted above, however, resource and other constraints preclude this for many, probably most, academics.

Face to face meetings are seen as a more feasible, albeit secondbest, alternative for enabling academics to keep abreast of policy developments. However, neither meetings nor co-location and coproduction remove the process of translation from the process, but rather make it oral (rather than written) and immediate. Even where there is a shared language (or at least mutual comprehension) between academics and civil servants, the differences in their primary concerns (Wingens, 1990) still affect how they can make sense of each other. This was very visible in the meetings we organised bringing academics, GSRs and policy teams together. When (following normal practice) academics presented first, translating their own work without a detailed brief, civil servants almost always struggled to see its relevance. In contrast, when we reorganised and started with civil servants presenting their current concerns, academics generally were better able to respond by translating their knowledge instantly into something comprehensible and useful.

When research is commissioned or coproduced, the closer relationship between academics and civil servants might plausibly help the former to be more adept at translating their own work. Yet even then they may struggle to write effectively. Doing so requires making the relevance to the civil servants' work obvious. A GSR contrasted two of our responses to the same brief: one which in setting out "principles of democratic problem solving... is potentially very helpful to guide policy", while the other was criticised for being "out of step with current policy debates...For the unfamiliar reader, why is Truth relevant?" Where the academic authors of the latter had aimed for a major reframing of the issue, through unsettling existing conceptualisations, the GSR response was to ask "whether some more thought could go into making the policy recommendations more in tune with where local and national policy makers see their key problems at the present time". Even clear briefs can be interpreted in ways which lead to inadequate translations of academic knowledge.

Being functional also means aligning with the civil servants' language (Reiss and Vermeer, 2013), and even the most policyoriented academics may find this hard, in part because of concerns over what is lost in translation (Freeman, 2009). One such scholar reflected that "you default to these modes of communication and structures of communication like the report or a journal article. Moreover, actually presenting it in a different way [to policy makers] can be quite a challenge". Another similarly reported how, in producing a policy briefing, their team "struggled... because they were trying to keep the clever and cultivated phrases...rather than just taking little bits and saying 'look, these are the key points, that bit doesn't matter'”. The GSRs recognised these concerns, even as they wrestled with "interesting" work in which they could see "academics trying to protect their intellect and not distil their findings into sort of ten key bullet points".

Overall, from this functionalist perspective the quality of a translation depends on its utility for the end user. The parallels between this idea, from Translation Studies, and the context of research use are obvious. In the latter, this means not only sharing the broad purpose of improving policy making, but also detailed knowledge of context and the possible function that translated research could serve. Empirically we saw how this was challenging for academics, and the difficulties involved in the normal, less interactive and unbriefed attempts to make research relevant show why ongoing engagement and dialogue are so important both for mutual understanding and feedback on translations. It is clear that translation takes place, however research use is organised. The difference between push/pull and interactive approaches is in who is involved, and so exactly where the boundary is across which translation takes place, and the extent to which the approach facilitates more or less functional translation.

However, functionalist translation theory has been criticised for over-emphasising the importance of the target audience's purposes (Nord, 2018). While it recognises the need for coherence, and the possibility that this might be based on equivalence, the hierarchy is clear: how much equivalence, and of what, is defined by the criterion of producing a functional translation. Judging and acting on this is a task for the translator, working with the users' needs in mind, with no in-principle restriction on creative license (Nord, 2018). One can easily see why academics have similar concerns about "policy-based" (Marmot, 2004) or "political" (Weiss, 1979) uses of their research-concerns reinforced by theorising which emphasises the idea of "betrayal" inherent in translation (Law, 1997; Rhodes and Lancaster, 2019).

A senior GSR summarised the ideal translation, suggesting the need to resolve the dilemma between the problems of privileging either equivalence or function:

The trick is to get the right balance between substance (showing that this is based on good evidence and/or theory), accessibility (making it easy for a busy person to get the most important messages out of a summary), and policy relevance (what does this mean for what we, or communities, actually do?) [email, original emphasis].

Trustworthiness is what matters here. Another GSR suggested that achieving this ideal does not mean that translations have to be complete: "What you're getting across often is the kind of tip of the iceberg, and you'll focus on that tip, but you're also conscious that you've got to have a very deep foundation that underpins that advice". This returns us to the question of what links source and target text: what might guarantee reliability, particularly in the absence of evidence contained within the translation itself?

Resolving the dilemma: function plus loyalty. Writing from within the Translation Studies functionalist tradition, Nord's response seems apposite in the context of research translation, providing both insight and guidance. Addressing the situation in which the author's and user's purposes are different, she invokes the concept of "loyalty" (Nord, 2018). In contrast to the inter-textual concept of equivalence, this is inter-personal "responsibility" towards translators' "partners in translational interaction", which takes into account the cultural expectations and "legitimate interests" of all those involved-author, translator and users (Nord, 2018, p. 117). It thus morally constrains a translator's freedom, to produce a text "compatible with the original author's intentions" (p. 115). Loyalty is closely bound to trust and reliability but is not the same: it is a moral orientation, which underlies, and is the precondition for, a trusting relationship.

This gets to the heart of why "relationships, trust, and mutual respect” (Oliver et al., 2014, p. 4) are found to be so important in 
successful research use (Oliver and Boaz, 2019). This was exemplified by one GSR's first question about us to his colleague, who was acting as our gatekeeper: "how do you know you can trust these people?" Interviewees' reasons for trusting, even where personal relationships were absent, included a generalised faith in academia as a system oriented towards objectivity and truth (in contrast to think tanks and other "evidence" sources, which were seen as being more politically motivated and biased) (cf. Wingens, 1990). There was also an explicit reliance on academics' descriptions of their research methodology, which are generally comprehensible to the GSRs, if not to the policy teams. In contrast, a generalised lack of trust in government precludes policy engagement for some academics (Pain, 2006), such as one who responded to a presentation of findings from this project by characterising the project team as "like Stasi informants".

Where interaction is involved, rather than merely translation of published research outputs, the personal issues go beyond methodological competence and again take on a moral tone. Sensitivity to the other's context, and particularly risks, were salient. Academics have to trust the GSRs and policy teams not to misrepresent their research, either with respect to its substantive claims or its validity and scope. Conversely, a policy team member told us

if you say the wrong thing to the wrong person, then that's a vulnerable, vulnerable thing. So there's a thing about trust there...And where we have kind of developed relationships, so, you know, we've worked with you before, that trust emerges over time doesn't it? And so we know we can say things to you guys that we might not say to just anyone I walked into, on entering a university building.

So why might translators be loyal in Nord's sense? There is obvious instrumental gain for GSRs in being seen to be purveying good research to the policy teams, but for many of those we interviewed the reasons went beyond this. Overlapping identities mattered for the civil servants who had been academics, and, crucially, there was something akin to Pain and her colleagues' "agreed common purpose" (Pain et al., 2015, p.11), though with a stronger moral connotation. This was captured by one GSR in the notion of a "shared endeavour": many in both "communities" believed academics and GSRs to be participating in the same project of helping make better policy. Cultivating such an ethos is clearly supported by face to face interaction (Oliver and Boaz, 2019) but this is not just about simple contact: personal characteristics and dispositions are important and there is often something intangible about how effective translational relationships are created. One participant in an academic/civil service "speed dating" event summed it up: "it's intellectual but it's also personal: it's 'who do I connect with?"”.

\section{Conclusions}

Overall, our empirical findings are unsurprisingly consistent with many other scholars' conclusions about the barriers to, and enablers of, the effective use of academic research. The purpose of this paper is, however, to further Oliver and Boaz's agenda in two linked ways: to broaden the scope of analytical attention beyond interactive approaches (such as knowledge brokering, partnerships and so on) to cover the normal (less than ideal) conditions of research translation, and to do this by putting at the centre of our attention the content, which is translated. We have done this by drawing on concepts drawn from the humanities discipline of Translation Studies, the home of much scholarship on the nature of translation yet almost entirely ignored by the research use community. We have necessarily been selective, and hope that this paper will serve as an introduction, which will prompt other scholars to use these and other ideas and approaches from Translation Studies ${ }^{3}$.
Of course, the details of how people behave-in our case in one division of one UK government ministry-are context (and thus case study) specific. Steiner (1998) was right that there can be no general theory of what is done at the moment of translation: it is situated practice, varying between organisational and normative contexts, and between policies and policy fields. However, there was nothing obviously special about the context we studied, and the insights into the nature of translation are very general: the same issues can be expected to recur elsewhere (Maxwell, 2012). This enables progress beyond merely providing "narratives of translational praxis" (Steiner, 1998, p. viii) to a set of middle-range concepts useful for investigating any research translation process. These are both analytical in that they should prompt questions about functions, equivalences and loyalties (and tensions between these), and normative in that these three concepts each lead to evaluative criteria. Future research could very usefully expand the range of our investigation to other fields and institutional settings, and also probe more deeply the nature of translational action in interactive settings involving partnerships and brokers.

Overall we argue that "translation" can be useful in understanding processes of research use, and should not be abandoned, as has been argued by scholars critical of simplistic, linear uses of the metaphor (Greenhalgh and Wieringa, 2011). Rather, drawing on the concepts from Translation Studies enables us to contribute to the already extensive research use literature, and in particular to augment the sophisticated study and promotion of interactive approaches. On the one hand, we deepen the analysis of what brokers, embedded researchers or participants in research partnerships actually do with the substantive content of research outputs. On the other, we broaden it to include the empirically dominant but much-criticised non-interactive forms of research transfer, suggesting that all "carrying across" between the academic and policy systems involves similar translation issues. What differs is exactly how the border is crossed, by whom, and what practices are possible to mitigate the inevitable challenges.

The conceptual argument can be summarised in terms of a dilemma and its proposed resolution. Thinking about equivalence between a source and its translation usefully emphasises what remains when a text is translated, and so what might be valued and justify the whole research translation endeavour. Despite its common-sense appeal, specifying what equivalence might entail in any context-independent way is problematic, and led Translation Studies scholars to appeal to function for the end-user as the guide for practice, with the appropriate equivalence between source and translation entirely context-dependent. This second horn of the dilemma is equally problematic, since in principle it allows a complete abandonment of fidelity to the content of a source. We find Nord's moral (rather than linguistic or semantic) resolution in terms of interpersonal loyalty persuasive and helpful, both in making sense of the importance of human relationships in research translation and in highlighting a more general moral commitment of the translator to all those involved, even in the least interactive research translation practices. By this account, a "good" translation of research would be sufficiently equivalent to the original ideas to be both functional for policy and respectful of the intentions and context of the researcher.

The analysis has practical implications, though we note that the collective understanding of research use tells us that our research will not straightforwardly influence practice. So while we suggest what might be done, we are under no illusions that actioning this will be easy! These implications are the importance of mutual and detailed understanding of, and empathy with, the needs, institutional context and risks of all involved, along with broadly shared fluency in each other's languages. This explains why face to face meetings and other forms of close interactions are so useful, and in contrast why academics translating their own material and 
disseminating it often do poorly both in terms of policy relevance and in building relationships. Both could be improved by paying attention to the micro-organisation of interactions to facilitate translation, and by the civil service providing readily accessible briefs on its pressing policy-relevant questions. These, along with some of the solutions frequently proposed in the research use literature (such as academics using more intelligible language) are likely to be necessary but not sufficient, unless academics also align themselves to the function of the civil service, or someone in the latter domain is able to take up academic research products and reorient them. Such intercultural communication work is difficult, and it is not obvious that academics should do it: they may well lack the specialist skills and capacity, and, despite the salience of the "impact agenda", there are career and reputational risks attached to engaging too closely with the policy world (Oliver and Cairney, 2019; Oliver and Boaz, 2019.)

In the UK context one implication of this is that the GSR profession should be more valued and more widely known within academia. More generally, investment to promote more effective research transfer should increase (and incentivise) opportunities for all those involved in research translation, as authors, translators or users, to learn about and (wherever possible) to meet the others, with the goals of promoting interpersonal relationships, generalised understanding and trust, and so of developing a basis for mutual loyalty and commitment to a shared endeavour.

\section{Data availability}

The materials generated and analysed during the current study are not publicly available, due to the sensitivity of some of the content and the need to preserve the anonymity of the civil servants involved.

Received: 29 June 2020; Accepted: 19 July 2021;

Published online: 03 August 2021

\section{Notes}

1 More or less similar cadres provide economic and scientific advice. Our research engaged exclusively with the GSRs, and it would be useful to explore the roles of the other specialisms in brokering other forms of knowledge and evidence.

2 Policy fields differ. While this lack of interaction seems normal in DCLG's areas of responsibility, in the health and education fields user-defined problems and interactive engagement seem more routine (Penuel et al., 2015; Vindrola-Padros et al., 2017; Ward et al., 2009).

3 Munday (2012) is a useful introduction and guide to the breadth of the discipline.

\section{References}

Adamska-Sałaciak A (2010) Examining equivalence. Int J Lexicogr 23(4):387-409

AHRC (2012) Connected communities. Arts \& humanities research council, Swindon. https://ahrc.ukri.org/research/fundedthemesandprogrammes/ crosscouncilprogrammes/connectedcommunities. Accessed 13 Jul 2021

Bandola-Gill J, Lyall C (2017) Knowledge brokers and policy advice in policy formulation. Handbook of policy formulation. Edward Elgar Publishing, Cheltenham, pp. 249-264

Bednarek AT, Wyborn C, Cvitanovic C, Meyer R, Colvin RM, Addison PFE, Close SL, Curran K, Farooque M, Goldman E (2018) Boundary spanning at the science-policy interface: the practitioners' perspectives.'. Sustain Sci 13 (4):1175-1183

Boswell C, Smith K (2017) Rethinking policy 'impact': Four models of researchpolicy relations. Palgrave Commun 3.44:1-10

Bradley Q (2015) The political identities of neighbourhood planning in England. Space Polity 19(2):97-109

Braun V, Clarke V (2006) Using thematic analysis in psychology. Qual Res Psychol 3(2):77-101

Callon M (1986) Some elements of a sociology of translation: domestication of the scallops and the fishermen of St Brieuc Bay. In: Law J (ed.) Power, action and belief: a new sociology of knowledge? Routledge, London, pp. 196-223

Caplan N (1979) The two-communities theory and knowledge utilization. Am Behav Scientist 22(3):459-470
Chesterman A (1997) Memes of translation: the spread of ideas in translation theory. John Benjamins Publishing, Amsterdam

Civil Service (2015) Civil Service Code. https://www.gov.uk/government/ publications/civil-service-code/the-civil-service-code. Accessed 28 May 2021

Civil Service (2021) About the Government Social Research profession. https:// www.gov.uk/government/organisations/civil-service-government-socialresearch-profession/about. Accessed 13 Jul 2021

Connelly S, Vanderhoven D, Durose C, Richardson L, Matthews P, Rutherfoord R (2015) Translation across borders: exploring the use, relevance and impact of academic research in the policy process. In: O'Brien D, Matthews P (eds) After urban regeneration: communities, policy and place. Policy Press, Bristol, pp. 181-198

Cooper AC (2016) Exploring the scope of science advice: social sciences in the UK government. Palgrave Commun 2(1):1-9

Court J, Young J (2003) Bridging research and policy in international development: an analytical and practical framework. Overseas Development Institute, London

Dewaele A, Vandael K, Meysman S, Buysse A (2021) Understanding collaborative interactions in relation to research impact in social sciences and humanities: A meta-ethnography. Res Eval, rvaa033. https://doi.org/10.1093/reseval/rvaa033

Engebretsen E, Sandset T, Ødemark J (2017) Expanding the knowledge translation metaphor. Health Res Policy Syst 15(19):1-4

Freeman R (2009) What is 'translation'? Evid Policy 5(4):429-447

Gaudreau M, Saner M (2014) Researchers are from mars; policymakers are from venus: collaboration across the system. Institute for Science, Society and Policy, University of Ottawa, Ottawa

Gluckman P, Wilsdon J (2016) From paradox to principles: where next for scientific advice to governments? Palgrave Commun 2, https://doi.org/10.1057/ palcomms.2016.77

Greenhalgh T, Wieringa S (2011) Is it time to drop the 'knowledge translation' metaphor? A critical literature review. J R Soc Med 104(12):501-509

Hampton S, Adams R (2018) Behavioural economics vs social practice theory: perspectives from inside the United Kingdom government. Energy Res Soc Sci 46:214-224

Hermans T (2000) Norms of translation. In: France P (ed.) The oxford guide to literature in english translation. Oxford University Press, Oxford, p 10-15

HM Treasury (2020) The Green Book: Central Government guidance for evaluation. HM Treasury, London

Hsieh H-F, Shannon SE (2005) Three approaches to qualitative content analysis. Qual Health Res 15(9):1277-1288

Ingold J, Monaghan M (2016) Evidence translation: an exploration of policy makers' use of evidence. Policy Polit 44(2):171-190

Kattirtzi M (2016) Providing a 'challenge function': Government social researchers in the UK's Department of Energy and Climate Change (2010-2015). Palgrave Commun 2, https://doi.org/10.1057/palcomms.2016.64

Kislov R, Hodgson D, Boaden R (2016) Professionals as knowledge brokers: the limits of authority in healthcare collaboration. Public Admin 94(2):472-489

Kislov R, Wilson P, Boaden R (2017) The 'dark side' of knowledge brokering. J Health Serv Res Policy 22(2):107-112

Kress G (2010) Multimodality: a social semiotic approach to contemporary communication. Routledge, London

Law J (1997) Traduction/trahison: Notes on ANT. Centre for Science Studies, Lancaster University, Lancaster

Lefevere A (1992) Translation, rewriting, and the manipulation of literary fame. Routledge, London

Lendvai N, Stubbs P (2007) Policies as translation: situating transnational social policies. In: Hodgson SM, Irving Z (eds) Policy reconsidered: Meanings, politics and practices. Policy Press, Bristol, p 173-189

Lindblom CE, Cohen DK (1979) Usable knowledge: Social science and social problem solving. Yale University Press, Cambridge

Marmot MG (2004) Evidence based policy or policy based evidence? Willingness to take action influences the view of the evidence-look at alcohol. BMJ 328:906

Matthews P, Rutherfoord R, Connelly S, Richardson L, Durose C, Vanderhoven D (2018) Everyday stories of impact: interpreting knowledge exchange in the contemporary university. Evid Policy 14(4):665-682

Maxwell JA (2012) Qualitative research design. SAGE, Thousand Oaks

Mitton C, Adair CE, McKenzie E, Patten SB, Perry BW (2007) Knowledge transfer and exchange: review and synthesis of the literature. Milbank Q 85(4):729-768

Mulgan G (2013) Experts and experimental government. In: Doubleday R, Wilsdon $\mathrm{J}$ (eds) Future directions for scientific advice in Whitehall. Cambridge Centre for Science and Policy, Cambridge, pp. 32-38

Munday J (2012) Introducing translation studies: theories and applications, 3rd edn. Routledge, London

Newmark P (1981) Approaches to translation. Pergamon Press, Oxford

Newmark P (1991) The curse of dogma in translation studies. Lebende Sprachen 36 (3):105-108

Nida EA (1964) Toward a science of translating. Brill Archive, Leiden

Nord C (2018) Translating as a purposeful activity: Functionalist approaches explained, 2nd edn. Routledge, London 
Nutley SM, Walter I, Davies H (2007) Using evidence: How research can inform public services. Policy Press, Bristol

Oliver K, Boaz A (2019) Transforming evidence for policy and practice: creating space for new conversations. Palgrave Commun 5:60. https://doi.org/10.1057/ s41599-019-0266-1

Oliver K, Cairney P (2019) The dos and don'ts of influencing policy: a systematic review of advice to academics. Palgrave Commun 5:21. https://doi.org/ 10.1057/s41599-019-0232-y

Oliver K, Innvar S, Lorenc T, Woodman J, Thomas J (2014) A systematic review of barriers to and facilitators of the use of evidence by policymakers. BMC Health Serv Res 14(2):1-12

Pain R (2006) Social geography: seven deadly myths in policy research. Prog Human Geogr 30(2):250-259

Pain R, Askins K et al. (2015) Mapping alternative impact: alternative approaches to impact from co-produced research. N8/ESRC Research Programme and Durham University, Manchester and Durham

Penuel WR, Allen A-R, Coburn CE, Farrell C (2015) Conceptualizing research-practice partnerships as joint work at boundaries. J Educ Stud Placed Risk (JESPAR) 20(1-2):182-197

Phoenix J, Atkinson L, Baker H (2019) Creating and communicating social research for policymakers in government. Palgrave Commun 5:98. https:// doi.org/10.1057/s41599-019-0310-1

Pielke RA (2007) The honest broker: making sense of science in policy and politics. Cambridge University Press, Cambridge

Reiss K, Vermeer HJ (2013) English edition: Towards a general theory of translational action. Routledge, London, (trans: Nord C) Original: Reiss K, Vermeer HJ (1984) Grundlegung einer allgemeinen Translationstheorie. Niemayer, Tübingen

Rhodes T, Lancaster K (2019) Evidence-making interventions in health: a conceptual framing. Soc Sci Med 238:112488

Rushmer R, Ward V, Nguyen T, Kuchenmüller T (2019) Knowledge translation: key concepts, terms and activities. In: Verschuuren $M$, van Oers $H$ (eds) Population health monitoring. Springer, Cham, p 127-150

Sakai N (2006) Translation. Theory, culture and society 23(2-3):71-78

Schäffner C (1997) From 'good' to 'functionally appropriate': Assessing translation quality. Curr Issue Lang Soc 4(1):1-5

Schäffner C (2018) Translation and institutions. The Routledge handbook of translation and politics. Routledge, London, p 204-220

Siggelkow N (2007) Persuasion with case studies. Academy of Management Journal 50(1):20-24

Smith KE, Joyce KE (2012) Capturing complex realities: understanding efforts to achieve evidence-based policy and practice in public health. Evid Policy 8 (1):57-78

Steiner G (1998) After babel: aspects of language and translation, 3rd edn. Oxford University Press, Oxford

Toury G (1995) Descriptive translation studies-and beyond. John Benjamins Publishing, Philadelphia

Vindrola-Padros C, Pape T, Utley M, Fulop NJ (2017) The role of embedded research in quality improvement: a narrative review. BMJ Qual Safety 26 (1):70-80

Ward VL, House AO, Hamer S (2009) Knowledge brokering: exploring the process of transferring knowledge into action. BMC Health Serv Res 9(1):1-6
Ward V, Tooman T, Reid B, Davies H, Marshall M (2021) Embedding researchers into organisations: a study of the features of embedded research initiatives. Evid Policy https://doi.org/10.1332/174426421X16165177580453

Wargent M, Parker G (2018) Re-imagining neighbourhood governance: the future of neighbourhood planning in England. Town Plann Rev 89(4):379-402

Weiss CH (1975) Evaluation research in the political context. Handbook of evaluation research. SAGE, London, p 13-25. Vol 1

Weiss CH (1979) The many meanings of research utilization. Public Admin Rev 39 (5):426-431

Wingens M (1990) Toward a general utilization theory: a systems theory reformulation of the two-communities metaphor. Sci Commun 12 (1):27-42

Woolf SH (2008) The meaning of translational research and why it matters. JAMA 299(2):211-213

\section{Acknowledgements}

The authors thank the civil servants involved in this study for their time and commitment, and their willingness to go "on the record" about their practices. Jane Woodin of the University of Sheffield's School of Languages and Cultures provided the all-important introduction to Translation Studies. We also acknowledge the support from the UK Research Councils who funded the Translation across Borders project through Connected Communities grant AH/L013223/1.

\section{Competing interests}

The authors declare no competing interests.

\section{Additional information}

Correspondence and requests for materials should be addressed to S.C.

Reprints and permission information is available at http://www.nature.com/reprints

Publisher's note Springer Nature remains neutral with regard to jurisdictional claims in published maps and institutional affiliations.

Open Access This article is licensed under a Creative Commons Attribution 4.0 International License, which permits use, sharing adaptation, distribution and reproduction in any medium or format, as long as you give appropriate credit to the original author(s) and the source, provide a link to the Creative Commons license, and indicate if changes were made. The images or other third party material in this article are included in the article's Creative Commons license, unless indicated otherwise in a credit line to the material. If material is not included in the article's Creative Commons license and your intended use is not permitted by statutory regulation or exceeds the permitted use, you will need to obtain permission directly from the copyright holder. To view a copy of this license, visit http://creativecommons.org/ licenses/by/4.0/

(C) The Author(s) 2021 